\title{
A study of vitamin D levels and associated deficiency in pregnancy and its effect on maternal and fetal outcome
}

\author{
Anupama Dave $^{1 *}$, Monica Verma ${ }^{1}$, Neelam Jain ${ }^{1}$, Atisha Dave ${ }^{2}$ \\ ${ }^{1}$ Department of Obstetrics and Gynaecology, MGM Medical College, Indore, Madhya Pradesh, India
}

${ }^{2}$ MBBS Student, Sri Aurobindo institute of Medical Sciences, Indore, Madhya Pradesh, India

Received: 26 September 2016

Revised: 11 November 2016

Accepted: 15 November 2016

\author{
*Correspondence: \\ Dr. Anupama Dave, \\ E-mail: anupamadave10@gmail.com
}

Copyright: () the author(s), publisher and licensee Medip Academy. This is an open-access article distributed under the terms of the Creative Commons Attribution Non-Commercial License, which permits unrestricted non-commercial use, distribution, and reproduction in any medium, provided the original work is properly cited.

\begin{abstract}
Background: From conception the embryo is dependent on the mother for all nutritional requirements until birth. Vitamin D deficiencies have adverse effect on pregnancy outcome result in poor growth, prematurity, NTD, even congenital anomalies. The aim and objectives of the study was to assess the prevalence of deficiencies among pregnant woman attending M.Y. Hospital and assess the correlation with the pregnancy complications.

Methods: Total 110 patients were studied for vitamin d levels and associated obstetrical complications and risk factors over a period of six months. 53 pregnant women were found to be deficient with vitamin D.

Results: 53 pregnant women out of total of 110 were deficient in vitamin D levels. Maximum patients belonged to group (21-30yr) of age. Vitamin D deficiency was more in housewives (65.3\%) and in urban(86.8\%). Low birth weight $<2.5 \mathrm{~kg}$ were born 50(45.5\%) and 2 IUD. 2 were diagnosed NTD in USG reports. $80 \%$ low birth weight babies were born in vitamin $\mathrm{D}$ deficient women.

Conclusions: Our study fails to show a causal relation between low vitamin D level and adverse maternal and fetal outcome in terms of preeclampsia, cesarean delivery, oligo and diabetes. There was a relation between vitamin $\mathrm{D}$ deficiency and low birth weight babies.
\end{abstract}

Keywords: Fetal and Maternal outcome, Pregnancy, Vitamin D

\section{INTRODUCTION}

Vitamin D has an increasingly recognised repertoire of nonclassical actions, such as promoting insulin action and secretion, immune modulation and lung development. It therefore has the potential to influence many factors in the developing fetus. A consensus on "target" 25-OHD levels in pregnancy is lacking, and the role of vitamin D supplementation in the prenatal period and during pregnancy and lactation is unclear. Furthermore, there is little evidence on "optimal" supplement dosing. Vitamin D supplementation has the potential to be a simple intervention with significant benefits.

Vitamin D, the sunlight vitamin is gradually becoming deficient in women and children. Lack of vitamin D has been linked to diabetes and increased rates of cesarean section births and pre eclampsia. ${ }^{1-3}$ In children, the deficiency can cause rickets and soft bone disease.

The burden of multiple repeated pregnancies, malnutrition, socioeconomic factors, adolescent pregnancies, traditional dietary practices, job related irregular and junk food habits, predisposes to micronutrients deficiency.

Data's on study of vitamin D deficiency are limited. Hence we conduct a study to assess the prevalence of deficiencies among pregnant woman attending MY hospital. Findings of our study will have relevance to the development of strategies for prevention of deficiency of these nutrients among pregnant women. These will help 
to introduce guidelines for vitamin D supplements in pregnancy. These deficiencies can be largely prevented if properly addressed.

The aim of the study was to study prevalence of vitamin $\mathrm{D}$ deficiency in pregnancy and its relationship with sociodemographic and dietary intake and correlate the maternal complications and evaluate perinatal outcome.

\section{METHODS}

The study is undertaken among patients attending OPD and admitted in Obstetrics and Gynaecology Department of M.Y. Hospital and M.G.M College Indore over a period of six months.

\section{Sample size}

110 patients were included 28 wks to 40 wks of gestational period. Information on age, education, parity, occupation, income and obstetric history was obtained from the mother using a close ended questionnaire. Gestational age (in weeks) at enrolment was calculated from the reported first day of the last menstrual period. Gestational age at birth was calculated using an ultrasonography report. Diet history was taken regarding being vegetarian, mix vegetarian (includes consumption of egg) and non-vegetarian taking meat, chicken, fish. History of iron and calcium intake was also taken. Blood investigations hemoglobin, MCV, hematocrit, and serum vitamin D was done. Any complain related like numbness, bony pain, neurological symptoms generalized weakness was asked. High risk factors like anemia, preeclampsia, diabetes, were identified. Patients were followed-up for mode of termination normal deliver/ LSCS/ PTL/SVD, baby weight was measured at birth and babies looked for any congenital anomaly.

Analyses of plasma vitamin D were done. The deficiency value of vitamin D was less than $20 \mathrm{ng} / \mathrm{ml}$, insufficiency (20-30ng/ml), sufficiency (30-100ng/ml).

\section{Statistical analysis}

Data were collected through specially designed proforma after explaining taking verbal consent. Descriptive data are presented as number and percentages with mean and standard deviation wherever required.

Chi-square test was used for analyzing categorical data. Student's ' $t$ ' test was used for comparing mean between two groups. A p-value of 0.05 or less was considered statistically significant.

\section{RESULTS}

The present study is undertaken among patients attending M.Y.H. OPD or admitting in antenatal ward in department of Obstetrics and Gynecology M.Y. Hospital,
MGM Medical College Indore over a period of six months.

Total no. of cases was 110 . These were subjected to vitamin D levels and 53 were found to be deficient in the vitamin D levels.

Table 1: Dietary habits.

\begin{tabular}{|lll|}
\hline Food habit & $\begin{array}{l}\text { Number of } \\
\text { patients }\end{array}$ & Percentage \\
\hline Vegetarian & 42 & 38 \\
\hline $\begin{array}{l}\text { Frequent non } \\
\text { vegetarian }\end{array}$ & 44 & 40 \\
\hline $\begin{array}{l}\text { Infrequent non } \\
\text { vegetarian }\end{array}$ & 24 & 21.8 \\
\hline Milk consumption & 45 & 40.90 \\
\hline
\end{tabular}

Table 2: Demographic factors.

\begin{tabular}{|lll|}
\hline Variables & Total $(\mathbf{n})$ & $\mathrm{CD}(\mathrm{n}=53) \mathrm{n} \%$ \\
\hline Age $<30 \mathrm{yr}$ & $74(67.2)$ & $37(50.0)$ \\
$>30 \mathrm{yr}$ & $36(32.7)$ & $16(44.8)$ \\
\hline Education Ill & $17(15.5)$ & $12(70.6)$ \\
Primary-sec & $35(31.8)$ & $20(57.14)$ \\
$>$ secondary & $58(52.7)$ & $21(36.2)$ \\
\hline Housewife & $68(62)$ & $35(51.47)$ \\
Working & $42(48)$ & $18(42.85)$ \\
\hline Urban & $94(86)$ & $46(48.94)$ \\
Rural & $16(14)$ & $07(43.75)$ \\
\hline Income $<10,000$ & $48(43.6)$ & $27(56.25)$ \\
$>10,000$ & $32(29.2)$ & $15(46.87)$ \\
$>20,000$ & $30(27.2)$ & $11(36.66)$ \\
\hline Exposure to sun & & \\
More & $42(38.1)$ & $18(42.85)$ \\
Less & $68(61.9)$ & $35(51.47)$ \\
\hline Supplement & & \\
Yes & $42(38.2)$ & $10.0(23.81)$ \\
No & $68(62.2)$ & $43(63.23)$ \\
\hline
\end{tabular}

Table 1 shows the dietary pattern followed by the women. From the semi-quantitative food frequency questionnaire, $42(38 \%)$ women never ate any nonvegetarian foods (egg, fish, chicken and meat) and only $24(21.8 \%)$ ate non-vegetarian foods at least every second day. Milk consumption was also low and 45 consumed milk less than every second day; the average portion size of milk was $150 \mathrm{ml}$. Though the consumption of milk must not be related to the vitamin D levels, but the dependent calcium metabolism and sequelae are important and need to be addressed properly.

Table 2 shows the socio-demographic characteristics and life style habits of the studied pregnant women according to vitamin D. Nearly half of the studied pregnant women had vitamin D deficiency $(48.2 \%)$. Younger women below 30yrs $(50 \%)$, housewives $(51.5 \%)$ and those with low income (56.25) were significantly more likely to 
have lower vitamin D compare with those of higher socioeconomic status. Lack of education was also associated with vitamin D deficiency (70.6\%) as compared to literate. Vitamin D deficiency was higher in pregnant women who had less exposure to sun $(51.47 \%)$ and not taking vitamin D supplements (63.23\%), as expected.

Table 3: Vitamin D deficiency in high risk patient.

\begin{tabular}{|lll|}
\hline Variable & $\begin{array}{l}\text { Normal vitamin } \\
\text { D level }\end{array}$ & $\begin{array}{l}\text { Vitamin D } \\
\text { deficiency }\end{array}$ \\
\hline $\begin{array}{l}\text { Anemia }<11 \\
\text { gm\% }\end{array}$ & 56 & 30 \\
\hline $\begin{array}{l}\text { Tingling and } \\
\text { numbness }\end{array}$ & 28 & 07 \\
\hline GHTN & 13 & 08 \\
\hline Bony pain & 37 & 21 \\
\hline $\begin{array}{l}\text { Oligo and } \\
\text { IUGR }\end{array}$ & 55 & 35 \\
\hline Diabetes & 02 & 02 \\
\hline Cong anomaly & 02 & 02 \\
\hline
\end{tabular}

Table 4: Mode of delivery.

\begin{tabular}{|llll|}
\hline Mode & $\begin{array}{l}\text { Total } \\
\text { Number }\end{array}$ & $\begin{array}{l}\text { Normal } \\
\text { level }\end{array}$ & $\begin{array}{l}\text { Vitamin D } \\
\text { deficient }\end{array}$ \\
\hline $\begin{array}{l}\text { Vaginal } \\
\text { delivery }\end{array}$ & 88 & 49 & 35 \\
\hline LSCS & 22 & $8(16 \%)$ & $11(23.91 \%)$ \\
\hline
\end{tabular}

Table 5: Outcome of babies.

\begin{tabular}{|llll|}
\hline $\begin{array}{l}\text { Birth } \\
\text { weight }\end{array}$ & Total & $\begin{array}{l}\text { Normal } \\
\text { level }\end{array}$ & $\begin{array}{l}\text { Vitamin D } \\
\text { deficient }\end{array}$ \\
\hline$>2.5 \mathrm{KG}$ & 58 & $45(75 \%)$ & $13(22 \%)$ \\
\hline$<2.5 \mathrm{Kg}$ & 50 & $10(20 \%)$ & $40(80 \%)$ \\
\hline IUD & 2 & 2 & 0 \\
\hline NTD & 2 & 0 & 2 \\
\hline
\end{tabular}

Table 3 shows the vitamin D levels in the high risk patients. There was no significant association in the women with anemia which was more in those with normal vitamin D levels (56) as compared to the vitamin $\mathrm{D}$ deficient women (30). Same was the case with symptoms like tingling and numbness, bony pain and pregnancy specific conditions like gestational hypertension, oligohydramnios, IUGR, diabetes and congenital malformations. The conditions were comparable in the two groups and no significant association with the high risk factors could be seen.

Table 4 is important in the terms of mode of delivery as we expect a higher rate of cesarean section in vitamin D deficient women due to a defective pelvis and bony malformations or borderline CPD. The findings were as expected. Rate of cesarean was higher in the vitamin D deficient group (23.9\%) as compared to the women with normal vitamin D levels (16\%).

Table 5 describes the outcome of babies in relation to vitamin D deficiency. Growth restriction was more common in the vitamin D deficient women who delivered more $(80 \%)$ low birth weight babies $(<2.5 \mathrm{kgs})$. The maternal deficiency seems to be affecting the baby growth in utero.

\section{DISCUSSION}

\section{Vitamin D deficiency}

A study conducted in South Carolina found $41 \%$ of pregnant women were deficient in vitamin $\mathrm{D}(25(\mathrm{OH})$ $\mathrm{D}<50 \mathrm{nmol} / \mathrm{L})$ and another $41 \%$ of pregnant women were insufficient in vitamin D $(25(\mathrm{OH})$ D $50-80 \mathrm{nmol} / \mathrm{L})$ during early pregnancy. ${ }^{4}$ Another Pennsylvania study found $62 \%$ of Caucasian pregnant women and $96 \%$ of African American pregnant women were deficient or insufficient $(25(\mathrm{OH}) \mathrm{D}<80 \mathrm{nmol} / \mathrm{L})$ in vitamin $\mathrm{D}$ during early pregnancy. ${ }^{2}$ A small study examined the prevalence of vitamin D deficiency and insufficiency in 80 pregnant African American adolescents and revealed that 52\% and $36 \%$ of African American adolescents were low $(25(\mathrm{OH}) \mathrm{D}<50 \mathrm{nmol} / \mathrm{L})$ in vitamin $\mathrm{D}$ during the second and third trimester respectively. ${ }^{5}$

Our study revealed that vitamin D deficiency prevalence was $48.2 \%$ among pregnant women.

\section{Demographic status}

Vitamin D deficiency is very common in pregnancy it was observed that vitamin $\mathrm{D}$ deficiency was more in housewives $(65.3 \%)$ and in Urban $(86.8 \%)$. Younger women below 30 years old $(43.2 \%, \mathrm{P}=0.032)$, housewives $(65.3 \%, \mathrm{P}=0.008)$, and those on low monthly household incomes (QR5,000-9,999) $(49.2 \%, \mathrm{P}$ $=0.03$ ) were significantly more likely to have lower vitamin D compared with those who had sufficient vitamin D levels in Doha study.,6

In study by Bener A Exposure to sunlight $(63.4 \%, \mathrm{P}=$ $0.05)$, daily physical activity $(64.4 \%, \mathrm{P}=0.05)$, and vitamin D supplement intake $(89.7 \%, \mathrm{P}<0.001)$ were significantly lower in deficient pregnant women. ${ }^{1,6}$

It was observed in our study that more exposure to sun (38.1\%) and supplement of vitamin D intake (38.2\%) have less deficiency than those who are more exposure to sun and took supplement. The risk of vitamin D deficiency was higher in housewives and those with low monthly household income. The deficiency being sunlight exposure dependant also has a predilection with religion. The burqa practice in the Muslim community is more prone to vitamin $\mathrm{D}$ deficiency. 
In this study vitamin D deficiency was comparable in relation with oligo, IUGR, DM, GHTN, and congenital anomaly as compared to the women with normal vitamin D levels.

\section{Increased cesarean delivery rates}

Vitamin D deficiency ( $<37.5 \mathrm{nmol} / \mathrm{l})$ has been associated with a four-fold increased risk of primary caesarean section (caesarean section performed for the first time), although this has not been demonstrated in all studies. Merewood et al measured vitamin D concentrations of 253 mothers after delivery. ${ }^{7}$ They reported that the risk for primary cesarean section in women with vitamin D concentrations $<37.5 \mathrm{nmol} / \mathrm{L}$ was almost four times higher than women with higher vitamin D concentrations. They proposed maternal vitamin D status may be associated with risk for primary cesarean section through calcium's role in the initiation of labor, or by increasing preeclampsia risk. Studies revealed a significant increase in maternal serum calcium concentrations at the time of vaginal delivery. ${ }^{8}$

Our study shows an association of vitamin D deficiency and cesarean deliveries. $23.5 \%$ women delivering by cesarean had vitamin D deficiency but this association is not statistically correlated. Segregating the vitamin D deficiency with the indications of cesarean section will be more important to understand the role of vitamin $\mathrm{D}$ in initiation of labor or association with the calcium metabolism.

\section{Pre-eclampsia}

There is conflicting evidence whether hypovitaminosis D in pregnancy is associated with hypertension and preeclampsia. In three studies, women who developed preeclampsia were found to have lower levels of vitamin D than women who did not with levels less than $50 \mathrm{nmol} / \mathrm{l}$ associated with a five-fold increased risk of severe preeclampsia. ${ }^{9-11}$ In our study findings revealed that maternal vitamin $\mathrm{D}$ deficiency in pregnancy is not significantly associated with elevated risk for preeclampsia. Out of 21 patients that had gestational hypertension, only 8 had vitamin D deficiency. This forms around $38.09 \%$ of all hypertension patients. Many studies have shown a weak or no relationship between vitamin $\mathrm{D}$ and hypertensive disorders in pregnancy just like ours. Hence the supplementation of vitamin $d$ in pregnancy for prevention of pre eclampsia is not recommended.

\section{Low birth weight}

Maternal vitamin D levels have been shown to positively correlate with birthweight centile. ${ }^{12}$ In a study from Holland, women with vitamin D deficiency had a 2.4-fold increased risk of having an SGA baby. ${ }^{13}$ In our study the patients of vitamin D deficiency delivered more growth restricted babies $(80 \%)$.

\section{Impaired glucose tolerance}

The risk of glucose tolerance depends on the variations of ethnicity. There are some data to suggest that the association between 25(OH)D levels and GDM risk is specific to ethnicity. In a majority non-Hispanic white population, $25(\mathrm{OH}) \mathrm{D}$ concentrations at 16 weeks of gestation were significantly lower in GDM subjects than in controls, whereas no association was found in Indian mothers where $25(\mathrm{OH}) \mathrm{D}$ concentrations were measured at 30 weeks of gestation. ${ }^{14}$ In our study only 2 patients had gestational diabetes and both had vitamin D deficiency. This is a very small sample size to comment on the association of glucose tolerance and vitamin D deficiency.

\section{CONCLUSION}

Routine screening of maternal vitamin D deficiency demonstrates the importance of detecting and treating maternal vitamin $\mathrm{D}$ deficiency during pregnancy in atrisk patients. Failure to diagnose and institute treatment may carry significant risks to both mother and child which need to be researched and followed.

Our review, after summarising existing data of this study, fails to show a causal relation between low vitamin D level and adverse maternal and neonatal outcome in terms of hypertension, anemia, cesarean section rates, diabetes or bony pain. Lack of vitamin D in pregnant women has been linked to GDM, Preeclampsia, and increased rate of LSCS birth. While babies can be LBW or smaller than average in children this deficiency can lead to Rickets and soft bone disease in future, in pregnant women deficiency may cause or associated with spontaneous abortion, IUGR, IUD, preeclampsia, pre-term labor and anemia while in new born LBW, NTDs or congenital anomalies (spina bifida, anencephaly etc.) Anemia other developmental defects and even can sometimes lead to temporarily infertility.

Low level serum vitamin D have been documented among pregnant women in India who habitually are vegetarian or mix non vegetarian taking small proportion of non-veg food. Along with it low socio economic status, lack of nutritional awareness, women with limited sun exposure and with darker skin tone and of course inadequate vitamin and other nutrient supplementation during preconceptional and pregnancy period. Many randomized controlled trials of vitamin D supplementation initiated early in pregnancy demonstrate that vitamin D supplementation might reduce the incidence or severity of complication likes GDM, Preeclampsia LBW, Births, IUGR, NTDs, Anemia etc.

On the contrary many scholars and researchers have now started questioning the association of vitamin D deficiency with every medical disorder possible. For that matter associations have been reported with thyroid disorders, cardiac disorders and also pregnancy related 
complications. It is now thought to raise the normal level criteria for vitamin D. Vitamin D deficiency and associated complications are seen very rarely in the individuals unless the deficiency is very severe. Hence to conclude our study does show a relation of low birth weight baby and vitamin D deficiency but it fails to show relation with other high risk factors of pregnancy.

Funding: No funding sources

Conflict of interest: None declared

Ethical approval: The study was approved by the Institutional Ethics Committee

\section{REFERENCES}

1. Bodnar LM. Maternal Vitamin D Status and the Risk of Mild and Severe Preeclampsia. Epidemiology. 2014;1.

2. Merewood A, Mehta SD, Chen TC, Bauchner H, Holick MF. Association between vitamin D deficiency and primary cesarean section. J Clin Endocrinol Metab. 2009;94(3):940-5.

3. Burris HH. Vitamin D and Gestational Diabetes Mellitus. Curr Diab Rep. 2014;14(1):451.

4. Bodnar LM, Simhan HN, Powers RW, Frank MP, Cooperstein E, Roberts JM. High prevalence of vitamin D insufficiency in black and white pregnant women residing in the northern United States and their neonates. J Nutr. 2007;137(2):447-52.

5. Bowyer L, Catling-Paull C, Diamond T, Homer C, Davis G, Craig ME. Vitamin D, PTH and calcium levels in pregnant women and their neonates. Clin Endocrinol (Oxf). 2009;70(3):372-7.

6. Bener A, Al-Ali M, Hoffmann GF. High prevalence of vitamin D deficiency in young children in a highly sunny humid country: a global health problem. Minerva Pediatr. 2009;61:15.

7. Farrant HJ, Krishnaveni GV, Hill JC, Boucher BJ, Fisher DJ, Noonan K, et al. Vitamin D insufficiency is common in Indian mothers but is not associated with gestational diabetes or variation in newborn size. Eur J Clin Nutr. 2009;63:646-52.

8. Black MM. Micronutrient deficiencies and cognitive functioning. Journal of Nutrition. 2003;133:3927S$31 \mathrm{~S}$.

9. Kolusari A, Kurdoglu M, Yildizhan R, Adali E, Edirne T, Cebi A, et al. Catalase activity, serum trace element and heavy metal concentrations, and vitamin A, D and E levels in preeclampsia. J Int Med Res. 2008;36:1335-41.

10. Baker AM, Haeri S, Camargo CA Jr, Espinola JA, Stuebe AM. A nested case-control study of midgestation vitamin D deficiency and risk of severe preeclampsia. J Clin Endocrinol Metab. 2010;95:5105-9.

11. Bodnar LM, Catov JM, Simhan HN, Holick MF, Powers RW, Roberts JM. Maternal vitamin D deficiency increases the risk of preeclampsia. J Clin Endocrinol Metab. 2007;92:3517-22.

12. Robinson CJ, Wagner CL, Hollis BW, Baatz JE, Johnson DD. Maternal vitamin D and fetal growth in early-onset severe preeclampsia. Am J Obstet Gynecol. 2011;204:556.e1-4.

13. Leffelaar ER, Vrijkotte TG, van Eijsden M. Maternal early pregnancy vitamin D status in relation to fetal and neonatal growth: results of the multi-ethnic Amsterdam Born Children and their Development cohort. Br J Nutr. 2010;104:108.

14. Zhang C, Qiu C, Hu FB, David RM, van Dam RM, Bralley A, et al. Maternal plasma 25-hydroxyvitamin $\mathrm{D}$ concentrations and the risk for gestational diabetes mellitus. PLoS One. 2008;3:e3753.

Cite this article as: Dave A, Verma M, Jain N, Dave A. A study of vitamin D levels and associated deficiency in pregnancy and its effect on maternal and fetal outcome. Int J Reprod Contracept Obstet Gynecol 2017;6:84-8. 